\title{
Incorporating the insurance value of peri-urban ecosystem services into natural hazard policies and insurance products: Insights from Mexico
}

\begin{abstract}
Understanding how to adapt to increasing risk under climate change is essential for governments wishing to mitigate harms and manage insurance and disaster assistance costs. An approach that values the public good of hazard mitigation provisioned by natural ecosystems could also incentivise government, beneficiaries and insurance companies to share responsibility and funding for targeted conservation and restoration. To illuminate this concept of the insurance value of ecosystems, it is important to map the relationship between the area(s) that benefit from and provide regulating ecosystem services and to identify what determines the level of protection. In the case of flood control regulation that benefits at-risk urban areas, upstream or inland peri-urban areas are key. We present steps to operationalise the insurance value in policy using spatial indicators of periurban biodiversity and vegetation and soil health for four Mexican cities. For Mexico City only, we identify at-risk areas and characterise upstream peri-urban areas and find this insurance value is already diminished. Combining spatial analysis with a damage cost function we estimate the expected damage costs of different flood events and the monetary value of enhancing this insurance value. This estimate could be compared to other policy interventions and integrated into hazard insurance.
\end{abstract}

Key words: insurance value, regulating ecosystem services, Mexico, natural hazard protection

\section{Introduction}


National governments are frequently the insurer of last resort for hazards. The flood protection and disaster assistance they provide may inadvertently generate a moral hazard whereby those at-risk perceive risks to be minimised and have no incentives to invest in further risk reduction (Gordon and Little, 2009). Natural ecosystems can provide hazard mitigation and may offer a new approach to share responsibility between government, beneficiaries and insurance companies through funding risk reduction. The concept of the insurance value of ecosystems combined with information on the spatial relationships between the areas providing regulating ecosystem services and those benefiting from them raises the profile of not just conservation lands but also peri-urban areas. In this article, we follow steps to: identify providing and benefiting areas of flood control regulating ecosystem services in four Mexican cities; characterise both the vulnerability of the benefiting areas and what in the providing peri-urban areas provides the insurance value; and estimate the expected monetary value of this insurance value for Mexico City.

The concept of a natural ecosystem's insurance value is its ability to continue providing ecosystem services even when disturbed, for instance by extreme events. The implicit value of certain regulating ecosystem services is the price differential for risk premiums homeowners or city authorities pay for having their property or infrastructure insured, and what they would have to pay if the existing risk-mitigating ecosystem services were somehow eroded (Baumgärtner, 2008; Quaas and Baumgärtner, 2008; Baumgärtner and Strunz, 2014; McPhearson et al., 2015; Pascual et al., 2015). The protective value of ecosystems like a forested watershed or a coral reef which mitigate risks downstream or to inland areas, is infrequently recognised in policy and financial instruments aimed to mitigate natural hazards (Quaas and Baugmgärtner, 2008; Kellet and Way, 2018).

Where an ecosystem is found to be relevant in the delivery of a regulating ecosystem service it is important to know what aspects of the ecosystem are critical. Using the example of forests, regulating ecosystem services associated with controlling water flows are positively related to 
biomass and forest quality (Styles et al., 2016; Figueroa and Pasten, 2015; Mueller et al., 2013). Fragmentation of forest habitat is a threat to biodiversity and therefore also to the provision of associated ecosystem services (Fischer et al., 2006).

Quaas and Baumgärtner (2008) also find that biodiversity reduces the variance of other ecosystem service flows. They conceptualise this as the natural insurance function of biodiversity. The insurance aspect of biodiversity is that the diversity of species within functional groups acts to increase response diversity, which reduces the negative impacts of external disturbances in terrestrial and aquatic ecosystems (Elmqvist et al., 2003).

Policy instruments used globally to protect habitats and biodiversity include the designation of National Parks and Terrestrial and Marine Protected Areas, as well as more novel schemes, such as Payment for Ecosystem Services (PES) that incentivise local people to conserve and restore habitats and their biodiversity. Yet, such activities cannot be restricted to protected areas (IPBES 2018). Rather there is a role to complement these policy instruments, through interventions directed to maintain and restore ecosystem function in other landscapes (Fischer et al., 2006), including periurban areas which are closer to human settlements and infrastructure.

Ecosystem services research in peri-urban areas highlights the importance of these natural spaces that serve as an interface between urban and rural territories (Morton et al 2014; McGregor et al. 2006; Czamanski et al., 2008). For instance, peri-urban ecosystems are important for provisioning ecosystem services (Harman and Choy, 2011) and for regulating ecosystem services, such as flood regulation (Barbedo et al., 2014). As Serna-Chavez et al. (2014), indicate there is a slope-dependent relationship with upstream peri-urban areas provisioning flood regulation to downstream benefiting urban areas. Yet peri-urban areas are under pressure from population growth, road construction and economic development that combined drive land cover and land use change (Su et al., 2014), 
and result in the deterioration and reduction in ecosystem service provision (McGreogor et al., 2006; Pisanti et al., 2009). New policy recommendations identify peri-urban areas with their mix of urban infrastructure, agriculture and natural ecosystems as priority areas for improved multifunctional landscape management (IPBES, 2018). Furthermore, in a climate change context, conserving or restoring natural ecosystems of peri-urban communities can reduce local and regional vulnerability (McPhearson et al., 2015).

Commercial insurance products could use information about the insurance value provided by periurban areas in combination with more typical information about at-risk populations and the protection offered by engineered flood control infrastructure. Governments, businesses and households purchase all manner of insurance to protect against loss (Heal, 2000), thus the insurance value provided by peri-urban ecosystems is theoretically one for which economic actors would pay. In the USA Muller et al. (2013) found evidence that beneficiaries are willing to pay to improve regulating ecosystem services that reduce the costs of disaster events. Our focus is how to quantify and estimate the insurance value provided by peri-urban areas for downstream urban areas. Soil conservation and preservation or restoration of biodiversity may act as a form of long-term insurance in reducing hazard risks. Yet urban dwellers and the governments that represent them are likely to be risk averse and therefore may prefer engineered flood control infrastructure, because they might not even consider nature-based options or are unsure about the magnitude of their benefits. Adapting an argument of Geaves and Penning-Rowsell (2016), a first step to invest in peri-urban land and biodiversity for flood regulation is to increase awareness of the existence and potential of insurance value in order that urban beneficiaries take responsibility and support incentives for peri-urban dwellers to preserve natural ecosystems for their benefit.

In thinking about how insurance products could credit investments in ecosystem restoration and conservation, consider the USA's National Flood Insurance Program (NFIP) Community Rating 
System (CRS, FEMA, 2018). The CRS provides a system of credit points for 19 flood protection and flood damage reduction activities. Flood prone communities use credit points to receive between $5 \%$ to $45 \%$ discounts on flood insurance premiums. There are four series of credit points activities: 1) public information; 2) mapping \& regulations; 3) flood damage reduction; and 4) flood preparedness. The total possible credit points across the series is 12,654 . Within each series are individual activities. For example, preservation of open space in series 2 is the third highest scoring activity (max. 2,020 credit points) and the stated objective is not only to preserve open space but also to keep floodplains undeveloped. Another high scoring activity is stormwater management (series 2, max. 755 credit points) which regulates new development in the watershed to prevent an increase in runoff and associated flood risk as well as to minimise soil erosion to protect water quality. The rating scheme provides an example of how communities can be incentivised to value the insurance values provided by ecosystems.

In developing countries, the lack of an insurance culture and poverty likely limits the feasibility of introducing such products. However, some middle-income countries are contracting with insurance companies to protect ecosystems to mitigate natural disasters, e.g. restoring the coral reef offshore Cancun, Mexico after damaging storms (Nature Conservancy, 2018; Harvey, 2017). Such examples are infrequent meaning that most often insurance value is provided for free as a public good. This is what Lamarque et al. (2011) term a 'non-marketed service' to beneficiaries. As public goods are often under-provisioned due to free-riding, policy neglect and lack of information (Kaul, 2011), we can expect that insurance value of ecosystem services is also under-provisioned.

Policy interest to (co-)design new insurance products and risk management policies requires operationalising insurance value information on what Fisher et al. (2009) note is an interdependence between ecosystem service providing and benefiting areas. The inclusion of the demand-side "for ecosystem services (i.e. the needs of beneficiaries)" (Lamarque et al., 2011: 791) 
often requires mapping the location of supply-side areas, and indicators have been created to show these spatial flows (Serna-Chavez, 2014). Studies have identified the relative density of these flows across landscapes to determine which benefiting areas are affected by upstream flow depletion of ecosystem services (Johnson et al., 2010). However, providing such information is unlikely to be straightforward in every instance as Martin-Ortega et al. (2013) find in their assessment of Latin American PES schemes. Where gaps in information to clearly define beneficiaries and providers hampers PES effectiveness.

Few studies have explicitly estimated insurance value (see Dallimer et al., this issue). One study by Figueroa and Pasten $(2015,446)$ theoretically estimate the value of natural insurance provided by forests by "evaluating the reduction (increase) in the insurance premium that risk-averse individuals are willing to pay when forest cover is marginally increased (reduced)". In the paper, we develop and apply an approach to empirically estimate the economic value of this insurance value that benefits Mexico City's peri-urban areas. Further, we quantify the flood control regulation provisioned by three other Mexican peri-urban areas. Key steps in consideration of the insurance value of peri-urban ecosystems are to: 1 ) identify key hazards; 2 ) identify and characterise providing and benefiting areas based on specific supply and demand indicators; and 3) map and overlay the supply and demand indicators to estimate the insurance value, its potential and to target any interventions.

Bagstad et al. (2013) recommend any spatial analysis of ecosystem service flows maps pairs that is the supply of and the demand for the ecosystem service, e.g. peri-urban areas that provision flood control to specific urban neighbourhoods. Mapping spatial relationships can reveal valuable information and its communication (Hauck et al., 2013) allows important details to be visualised. Indeed, maps capture information that often commands the attention of decision-makers in a manner that text and reports do not (de Groot et al., 2010). The goal is that such information on 
insurance value could inform strategic interventions to restore ecosystem services through targeted conservation and restoration policy.

The paper proceeds by describing the case study background, and then reports methods, particularly around what to measure to operationalise insurance values. The discussion covers how insurance products could be modified or introduced as an adaptation strategy. We end with recommendations for targeted regulating ecosystem service conservation and restoration policy.

\section{Case study}

Mexico is located, almost in equal parts, to the north and south of the Tropic of Cancer, this climate diversity, in combination with an extensive coastline and mountainous regions, explains the diversity of the nation's ecosystems (Sarukhan et al., 2009; Peterson et al., 2014). This also contributes to the nation's exposure to multiple natural hazards (INEGI, 2016), such as urban flooding and cyclone damage (World Bank, 2017). Risk can be explained by different factors, such as hazards, population size, economic activity, land use patterns, and infrastructure. However, in Mexico as elsewhere in the world, the number of disasters has increased significantly during the last decades (EM-DAT, 2018). Official data show that between 1999 and 2017, for every geological disaster there were 14 climate-related disasters and costs related to these were 10 times higher than for geological disasters (Proteccion Civil, 2018).

Conceptually, the economic value of natural insurance to Mexico is high; however, habitat destruction through land use conversion and fragmentation have had major impacts on degraded terrestrial ecosystems in Mexico (IPBES 2018; Sarukhan, et al., 2015). In the period between 1976 and 2011, Mexico lost 13.7 million hectares of natural vegetation, including jungles, forest, scrub and grasslands (SEMARNAT, 2016) due to different causes, including a rapid urbanisation (Cartron 
et al., 2005; Valdez et al., 2006). Not only is urban expansion a threat to biodiversity and regulating ecosystem services but so is neglect of peri-urban areas. Calderon-Contreras and Quiroz-Rosas (2017) found green infrastructure in Mexico City's peri-urban fringe was mostly of low quality, hindering the provision of regulating ecosystem services required for building Mexico City's resilience.

The large mosaic of landscapes with different land uses and diverse human communities, challenges conservation and restoration policies, and contrasts with traditional schemes of national parks or sparsely populated pristine environments seen in most developed countries (Sarukhan et al., 2015). The Mexican government promotes biodiversity conservation with various policy instruments, such as natural protected areas, PES and reforestation programmes, support to management units for wildlife conservation, and controls on illegal hunting of wildlife (OECD, 2013). National Programmes of Payments for Hydrological Services and for Biodiversity Services implemented by the National Forestry Commission (CONAFOR) include matching funds to support local communities and to promote local markets (Sarukhan et al., 2015). Nevertheless, there is an explicit objective to direct conservation activities and resources to areas with lower opportunity costs, i.e. to more remote areas (Muñoz-Piña et al., 2008). In practice, this means that natural ecosystems in peri-urban areas are exposed to potential loss as there are no explicit policy instruments that consider their specific characteristics.

Furthermore, as around $76 \%$ of rural land in Mexico is communally-owned and managed in ejidos, how ejidos are managed is critical (INEGI, 2016). Ejido, the Mexican common property model, can deliver, in certain contexts, social, economic and ecological benefits (Bray et al., 2006). Working with ejidos will be critical to developing incentives that protect the insurance value of peri-urban ecosystems. 
Mexico has an institutional framework for disaster preparedness involving risk assessment, risk reduction and the promotion of a culture of prevention. There is also disaster insurance. In 1996 the Mexican government created a fund for natural disasters - FONDEN - to which it transfers funds for disaster relief and reconstruction efforts (World Bank, 2017). To the best of our knowledge, for natural hazards there are four insurance schemes, of which the final one is the only insurance for nature scheme.

1. For hurricane risk, FONDEN provides insurance to state governments on the Atlantic and Pacific coasts (World Bank, 2011).

2. For urban floods, the Government of Mexico City has an insurance scheme with the insurer Insurance Mexican Group (Grupo Mexicano de Seguros). Under this scheme, flood insurance is available for households and for the government for affected infrastructure (Romero, 2017).

3. For farming and agricultural industries an insurance scheme managed by the federal government under the Attention of Natural Disasters (CADENA) Programme provides compensation to small farmers after catastrophic events. CADENA now covers 31 of the 32 states and criteria for eligible farmers were expanded in 2013. A total 12 million hectares was covered in 2013 up from 100,000 hectares in 2003. Approximately 71 percent of this area covers low income producers (FAO, 2016).

4. For the Cancun coastal area, there is a new insurance-for-nature product devised by The Nature Conservancy, The Rockefeller Foundation and Swiss Re in coordination with state and federal government. The objective is to protect $60 \mathrm{~km}$ of the Mesoamerican reef which in turn protects Cancun's beaches which are critical to the local and regional economy (Nature Conservancy, 2018; Harvey, 2017). Premiums are paid by local hotels and the federal and local governments, and pay outs will fund reef restoration after hurricane damage. 
The above-mentioned policies are designed by different government agencies to deal with specific hazards. As such they are not part of an integrated national strategy that considers current and future hazards and how to mitigate them and their associated damage. A more integrated and spatially informed approach to policy that relies on a conceptually sound understanding of the insurance value of natural ecosystems would be valuable. In the sections that follow we provide information relevant to design more innovative insurance products and policy for four at-flood risk Mexican cities through targeted investment in their peri-urban fringes.

\section{Method}

To study the insurance value of natural ecosystems in peri-urban areas we focus on the function of ecosystems to regulate the flows of water into urban areas. We build a database where we consider the spatial relationships between (upstream) providing and (downstream) benefiting urban areas. We estimate the natural insurance provided by peri-urban ecosystems using estimates of flood damage costs when upstream peri-urban areas are characterised by predominantly disturbed soil and higher runoff ratios. Figure 1 is a conceptual diagram of the method. This approach allowed us to quantify (runoff coefficient, population density) and qualify (marginality index, biodiversity richness) the provision and demand for flood control regulation. 


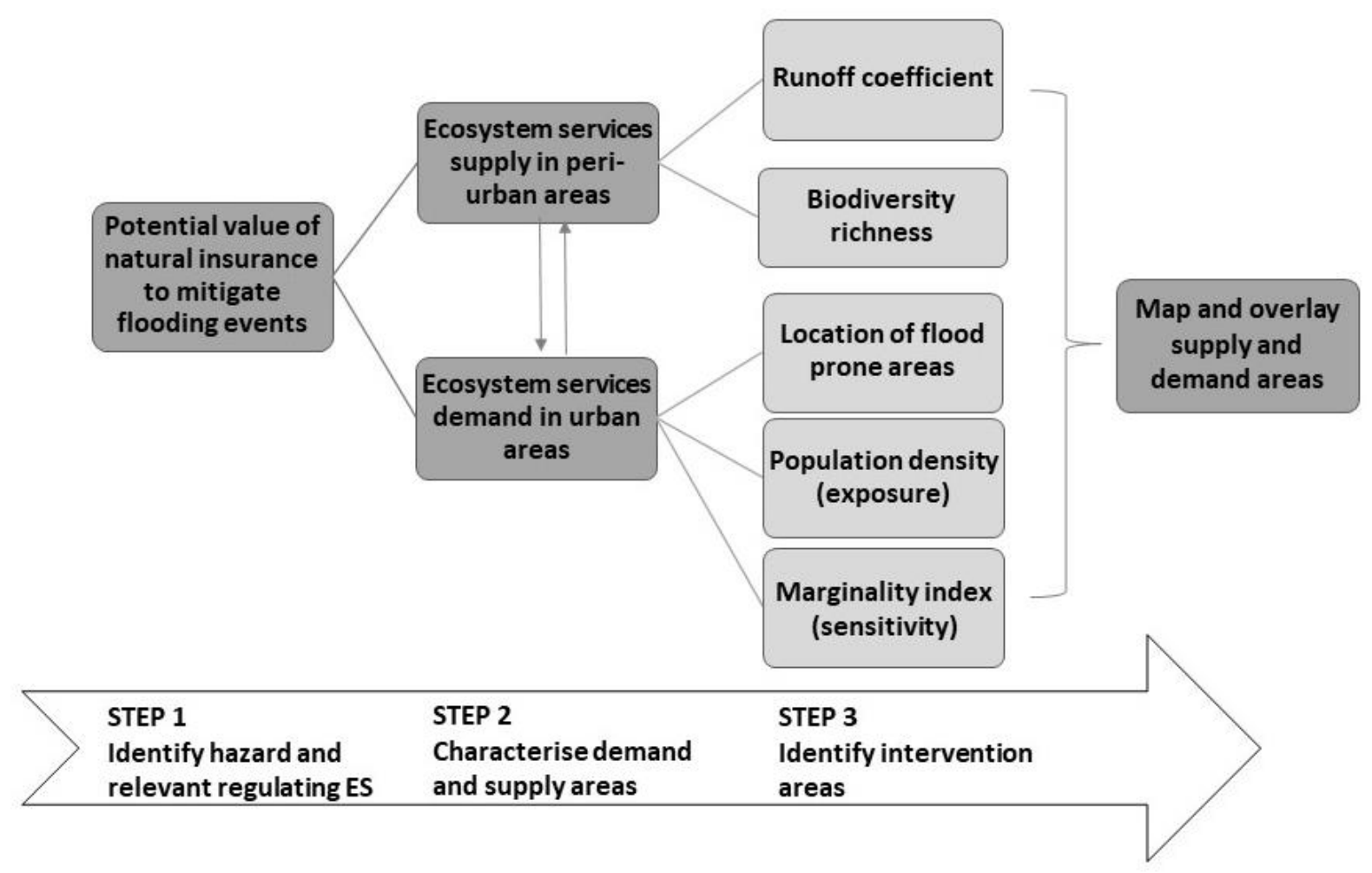

Figure 1: Conceptual diagram of the method

Step 1: Identify key hazards and relevant ecosystem services

The initial step is to identify key hazards in an area and relevant regulating ecosystem services. For instance, coastal cities are subject to hurricane risk and inland cities to flood risk. Climate classifications can be a first indicator of hazard exposure and we use a modified Köppen classification (García, 1998). However, more precise information is produced by the National Centre for Disaster Prevention and used here. Indices of hydrometeorological hazards for cyclones and droughts are classified in five categories (CENAPRED, 2012a; 2012b) and for flood hazard in four categories (CENAPRED, 2017). Of specific interest to the paper is a flood hazard index based on a return period of 5 years derived from information produced by the National Water Commission (CENAPRED, 2017). 
Next, in order to identify all relevant regulating ecosystem systems, it could prove useful to refer to the detailed descriptions and references in a database of ecosystem services, such as The European Environment Agency's CICES Version 5.1. For example, peri-urban areas might contribute to regulating water flows, thereby mitigating urban flooding and stopping landslides (CICES codes

\subsubsection{3 and 2.2.1.2).}

Step 2: Identify and characterise providing and benefiting areas

This is a key step to operationalise the insurance value of peri-urban areas. Specifically, it is necessary to identify suitable indicators for both regulating ecosystem service providing areas and the vulnerability of benefiting areas. All spatial analysis was conducted in ArcGis. For the datasets used and their resolutions see Table 1.

Table 1. Spatial data used to delineate ecosystem service provisioning and benefiting areas

\begin{tabular}{lll}
\hline Data (units) & Resolution & Source \\
\hline Vegetation cover (classified into five categories) & $1: 50,000$ & CONAFOR (2015) \\
Digital elevation model & $15 \mathrm{~m}$ & INEGI (2013) \\
Soils (classified into three categories) & $1: 250,000$ & INEGI (2014) \\
Biodiversity richness & $1: 1000000$ & CONABIO (2016) \\
$\begin{array}{l}\text { Priority terrestrial areas } \\
\text { Cyclone hazard }\end{array}$ & $1: 1000000$ & CONABIO (2004) \\
Drought hazard & $1: 200000$ & CENAPRED (2012a) \\
Flood hazard & $1: 200,000$ & CENAPRED (2012b) \\
Marginality index & Municipality level & CENAPRED (2017) \\
\hline
\end{tabular}


For providing areas runoff coefficients were calculated and by subtraction these quantify the proportion of rainfall in peri-urban landscapes that is potentially retained. The runoff coefficient in peri-urban areas was calculated based on the literature, considering three relevant factors: slope, soil texture and vegetation type and abundance (Cruz and Sotelo, 2013; Alfieri et al., 2014). The following assumptions were made: where there is more slope, there will be more runoff, where there is less vegetation there will be more runoff and where soil texture is finer there will be more runoff.

Slope was calculated using a digital elevation model and soil texture was reclassified into fine, medium and coarse, which are associated with low, medium and high infiltration rates, respectively. Vegetation cover was reclassified into five classes (dense forest and vegetation; pastures and open forests; shrubs; crops; no vegetation). These maps enabled the consideration of habitat fragmentation as a particular threat to the provision of ecosystem services (Fischer et al., 2006). The vegetation and soil texture data were combined with slope data to produce a two-dimensional matrix with which the percentage of runoff was calculated (Mendoza et al., 2002). Another key indicator to characterise providing areas was those areas designated as priority areas for conservation (CONABIO, 2016).

On the demand side three indicators denote urban vulnerability. They are: 1 ) information about the location of flood-prone areas. Such information could be based on past flood events or flood risk modelling. In Mexico official data on historic floods is only provided if the flood is declared a national disaster. In all other cases alternative information is needed. In 2016 and 2017 Mexico City flooded. To identify and locate neighbourhoods and principal avenues that were severely flooded we 
compiled information from newspaper articles. This information was subsequently crosschecked with official data. 2) Population exposed to flood risk is based on urban population density data (INEGI, 2010); and 3) the marginality index of urban areas which we use as a proxy of the vulnerability of at-risk populations. The marginality index is an aggregate measure of social deprivation calculated by the National Population Council. It comprises nine indicators that are grouped using principal components (CONAPO, 2010). In constructing the database to characterise the paired peri-urban and urban areas, our unit of analysis is the National Geostatistical Framework's Basic Geo-Statistical Areas (AGEB). All relevant variables and indicators, including other socio-economic and biophysical data were processed at the AGEB level. Each AGEB is classified as urban or rural. Urban AGEB are composed by blocks that range from 1 to 50 streets (INEGI, Manual de Cartografía Geoestadistica, 2010). For instance, we converted population density data from the 2010 Population and Housing Census from block level and the marginality index from the locality level (INEGI, 2010; CONAPO, 2010). Agricultural and unpaved areas can also provide regulating ecosystem services (Kremer et al., 2015) and these land covers are common in Mexican peri-urban areas. We therefore classify the soil and vegetation data into three categories: 1 ) disturbed (by development or construction), 2) cultivated (agricultural), and 3) natural (INEGI, 2014).

\section{Step 3: Map and overlay the supply and demand indicators to estimate the insurance value}

In the final step we test the indicator framework to assess the provision of flood control regulation in four peri-urban case studies: two inland cities, the Metropolitan Area of the Valley of Mexico City and Villa Hermosa (the capital of Tabasco State), and two coastal areas Acapulco (Guerrero) and Los Cabos (Baja California). In the Metropolitan Area of the Valley of Mexico City only, we apply the full framework considering both supply and demand indicators. The economic value of this insurance value was estimated by using an econometric function (Baro-Suárez et al., 2011) for different scenarios of flood depths correlated with the marginalization index. 


\section{Results}

Outputs of the spatial analyses include climate data and socio-economic characteristics for all 384 cities with 77,789 urban AGEB and 2,848 peri-urban AGEB. Table 2 reports the distribution of cities and peri-urban AGEB by climate type. Most cities are located in semi-warm sub-humid areas.

Table 2. Cities classified by climate type with examples

\begin{tabular}{|c|c|c|c|c|}
\hline & $\begin{array}{l}\text { Semi warm sub } \\
\text { humid }\end{array}$ & Warm arid & Temperate & Two categories \\
\hline Peri-urban AGEB & 131 & 92 & 47 & 95 \\
\hline \multirow[t]{4}{*}{ Example cities } & Cancun & Chihuahua & Morelia & Celaya \\
\hline & Coatzacoalcos & Hermosillo & San Cristobal de & Cuernavaca \\
\hline & Ciudad Valles & San Luis Potosi & las Casas & Queretaro \\
\hline & Uruapan & Zacatecas & Tlaxcala & Valley of Mexico \\
\hline
\end{tabular}

Around 10.1 million people, roughly $8.5 \%$ of Mexico's population, live in peri-urban areas. Periurban AGEB are distinct in terms of population density (lower), proportion of Indigenous people (higher), economic sectors (more agriculture, less commerce) and social indicators (more deprived) than urban AGEB. They are also characterised by comparatively abundant ecosystem services and they have a high proportion of natural (47\%) and cultivated soil (50\%). Table 3 presents descriptive statistics for urban and peri-urban AGEB of socio-demographic, environmental and economic characteristics.

Table 3. AGEB descriptive statistics 


\begin{tabular}{lrr}
\hline Characteristics & Peri-urban & Urban \\
\hline \# of AGEB & 2,848 & 60,324 \\
Socio-demographic characteristics & 10.2 & 86.8 \\
Total population, millions & 0.8 & 48.6 \\
Population density, persons per ha & 1.2 & 5.2 \\
Total Indigenous population, millions & 431 & 86 \\
$\quad$ average \# of people per AGEB & 3.5 & 8.9 \\
Education, years of education & 28.5 & 2.32 \\
Households with no electricity, average per AGEB & 173.4 & 11.45 \\
Households with no sewage service, average per AGEB & 1,291 & 472.8
\end{tabular}

\section{Environmental characteristics}

Disturbed soil, \%

$2.33 \quad 70.8$

Cultivated soil, \%

$50.4 \quad 16.4$

Natural soil, \%

$47.2 \quad 12.6$

\section{Economic characteristics}

Economic units in the primary sector (e.g. agriculture

$1.2 \quad 0.002$

and livestock)

$\begin{array}{lllll}\text { Economic units in the secondary sector (e.g. } & 0.59 & 0.57\end{array}$

manufacturing)

$\begin{array}{lll}\text { Economic units in the tertiary sector (e.g. commerce) } & 10.6 & 81.2\end{array}$

The descriptive statistics highlight that social marginality was greater in peri-urban areas which may increase the vulnerability of local communities to hazards and raises the role of in situ natural 
insurance. Table 4 shows indicators of hazards and biodiversity. Many cities are subject to hazard risk and more than half of peri-urban AGEB had high levels of ecosystem richness and almost twofifths are classified as priority areas for conservation. Therefore, any loss, fragmentation or degradation of habitats across peri-urban areas is likely to have acute implications for urban areas that benefit from peri-urban regulating ecosystem services.

Table 4: Urban hazards and peri-urban biodiversity, Number and percent of total

\begin{tabular}{lr}
\hline Indicator & \# of cities / AGEB \\
\hline Cities with high and very high risk of drought & 137 (36\%) \\
Cities with high and very high risk of cyclones & $28(7 \%)$ \\
Cities with high risk of flooding & $71(18 \%)$ \\
Cities with peri-urban AGEB with designated ecosystem richness & $219(57 \%)$ \\
Cities with peri-urban AGEB listed as priority areas for conservation & $145(38 \%)$ \\
\hline
\end{tabular}

We processed runoff coefficients for our four case study areas, see Figure 2. Peri-urban areas in The Valley of Mexico City had the highest runoff values ranging between 40 per cent and 70 per cent. Villa Hermosa has experienced severe flooding events, also has some high runoff values, with peak values between 50 and 60 per cent in western areas. Acapulco has peri-urban areas with low runoff values which coincide with a natural protected area, but values adjacent to urban AGEB are between 40 and 50 per cent. Finally, Los Cabos had the lowest runoff values across most of its peri-urban areas, ranging between 10 and 20 per cent. 

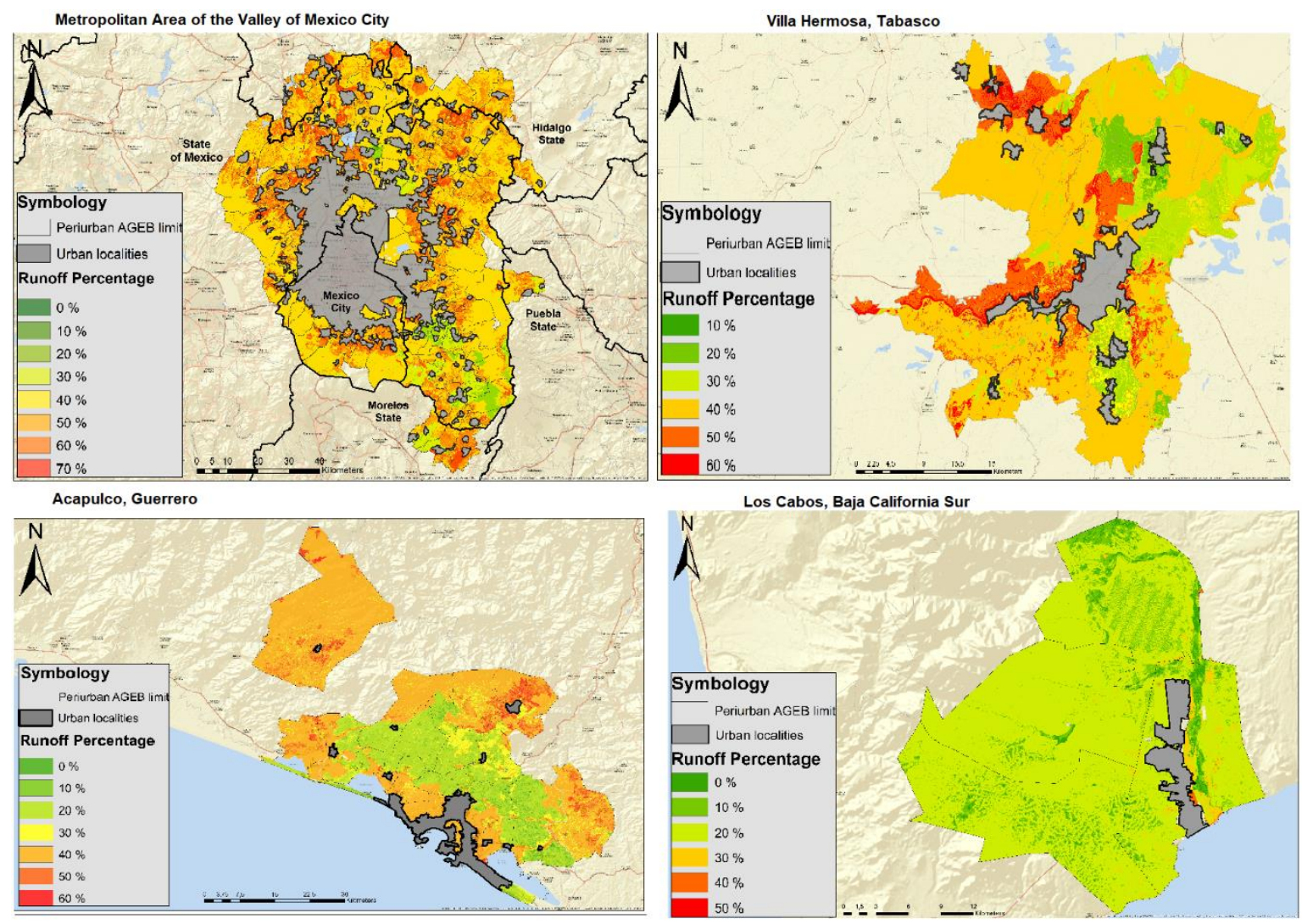

Figure 2: Urban and peri-urban AGEB in Mexico City, Villa Hermosa, Acapulco and Los Cabos

For hurricane risk the spatial relationship between benefiting and providing areas is also directional. Acapulco and Los Cabos, two Pacific coastal-tourist cities benefited from nearby forested slopes and coastal ecosystems that regulate water flows and provide storm and flood protection. In Acapulco, soils in the peri-urban area are $71 \%$ natural and $28 \%$ cultivated and the area is designated as medium or high priority for conservation. In Villa Hermosa soil in the peri-urban area is mostly formed of cultivated soil (77\%) and natural soil (21\%). Compared to Acapulco the predominance of cultivated soils might explain higher runoff coefficients. Here all the peri-urban AGEB are designated as high priority areas for conservation. 
For Mexico City, most of the peri-urban areas have rainfall runoff coefficients above 40 per cent. In Figure 2 it can be observed that the best conditions are in the southeast which is an upstream catchment that is protected by Izta-Popo National Park, in the neighbouring State of Mexico. In the southwest of the city there is a natural protected area called the Ajusco-Chichinautzin but it has higher runoff values, explained partly by relatively poorer vegetation condition. Of a total 164 periurban AGEB, 97 are designated as high or extreme priority areas for conservation. Although more than half of all Mexico City's peri-urban areas are natural protected areas there is acute pressure on them from urban expansion (Diaz-Chavez, 2006).

To determine the demand for flood regulation in urban areas, the first indicator is whether or not an area is flood-prone. However, only in the case of Mexico City could such data be collated. Flood prone neighbourhoods and principal avenues are designated with a triangle, see Figure 3. Our second indicator is population density which we use as a proxy for risk exposure. Several of the neighbourhoods affected by severe flooding are located in less densely populated areas (the light blue colour), and in most cases these are proximate to peri-urban areas with runoff coefficients above 40 per cent. 


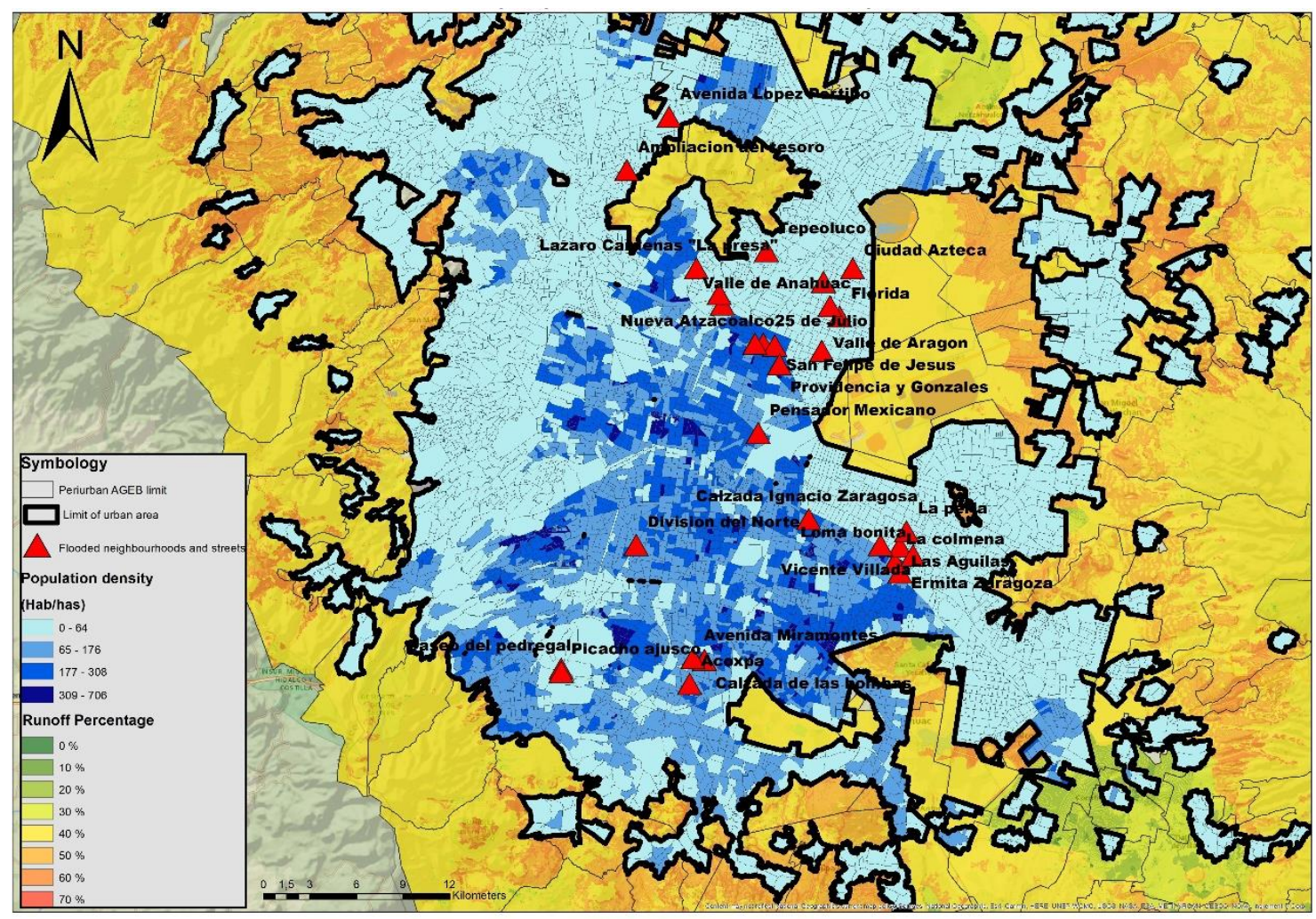

Figure 3: Runoff coefficients by peri-urban $A G E B$ and population density by urban AGEB in the Valley of Mexico City

Our third indicator for ecosystem services demand is the index of marginalization. Figure 4 shows that flood-prone neighbourhoods located in the northeast are also areas with medium to high marginalization.

There is insufficient official information on flood events and disaggregated damage cost estimates to use official data to estimate spatially explicit flood damage. More precise flood modelling in urban areas is required and is recommended for future research. To overcome data paucity, we utilise the econometric functions calculated by Baro-Suarez et al. (2011) to estimate the costs of flooding events, of different flood depths, to different types of households. For example, if 600 households were flooded to a depth of 30 centimetres in an area with a high marginality index (more deprived neighbourhoods), we estimate damages would be 26.92 million pesos (US\$1.41 million). However, 
if the 600 flooded households were in an area with a medium marginality index (better-off households), we estimate damages would be 40 million pesos (US\$2.1 million).

In the Valley of Mexico City upstream peri-urban natural and agricultural soils provide compromised flood control regulation to the downstream urban areas as illustrated by the high runoff coefficients in Figure 3. Targeted interventions could use information summarised in Figures 3 and 4 to improve outcomes in eastern and southern areas of Mexico City. Furthermore, modelled outcomes and the econometric functions in Baro-Suarez et al. (2011) could be used to estimate the value of specific interventions. For instance, if modelling indicated that tree planting interventions reduced runoff coefficients and corresponding flood depth from 30 centimetres to 20 centimetres, estimates of damage costs in an area with a high marginality index would decrease to 19.95 million pesos (US\$1.04 million) and in an area with medium marginality index to 26.89 million pesos (US\$1.41 million). To support policy that is more informed these estimates could be compared to the costs of maintaining or enhancing ecosystem service provision as well as to other options such as engineered flood control, floodplain storage or hazard insurance. 


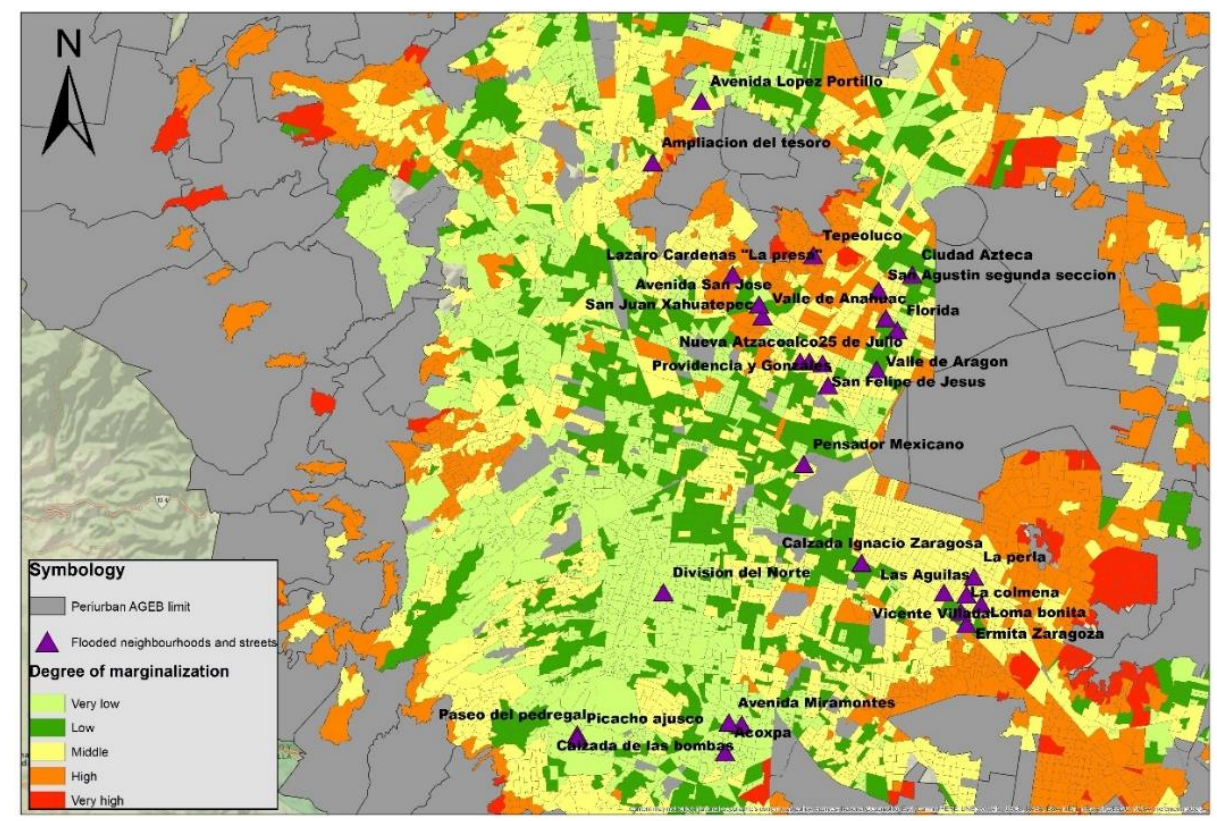

Figure 4: Degree of marginalization and flooded neighbourhoods and streets in Mexico City

Mexico City is the only Mexican city that has an insurance scheme which covers flooding of households and public infrastructure. In 2017 this scheme had a budget allocation of 212.5 million pesos (US\$11.1 million). Flood-prone neighbourhoods and avenues in the northern area of the Valley of Mexico City are located in the State of Mexico which is a separate jurisdiction without an insurance scheme and therefore the cost of flood damage must be assumed either by the State of Mexico or flooded households, or shared. The State of Mexico and potentially other city governments could improve flood recovery and preparedness if they likewise developed insurance schemes but schemes that also incorporate natural insurance. Moreover, the Mexico City scheme could be improved by more precise risk engineering if it also assessed investments to enhance the insurance value provided by peri-urban areas.

\section{Discussion}


Much of the insurance value literature is theoretical. The four case studies presented here aided our conceptualisation of how to operationalise insurance value in insurance schemes and policy around ecosystem services. In three of our four case study cities - Mexico City, Acapulco and Villa Hermosa - adjacent peri-urban areas have high runoff values, indicating a deterioration in water control regulation (Figure 2). As peri-urban areas in Mexico have differential potential to control rainfall runoff to urban areas other information is needed to operationalise the insurance value of ecosystems by considering the vulnerability of the demand areas. In our spatial analysis we estimated the potential economic value of flood control regulation that is provided by peri-urban ecosystems to urban dwellers in Mexico City.

The framework we present builds on studies that have explicitly evaluated the spatial relationship between ecosystem service providing and benefiting areas at a landscape scale (Fisher et al., 2009; Johnson et al., 2010; Bagstad et al., 2013; Serna-Chavez et al., 2014). Establishing where regulating ecosystem services are produced and who the beneficiaries are is critical information for operationalising the insurance value of peri-urban areas. As Johnson et al. (2010) indicate, mapping the directional flow of ecosystem services is the first step to a new approach in which landscapes are managed for ecosystem services, replacing current practice whereby ecosystems which provide unspecified ecosystem services are protected. Such an approach could support long-term decisionmaking around strategic land use planning and targeted investment in, and management of, natural ecosystems and soils in peri-urban areas. Combining information about risks and the directionality of benefits would target all three factors identified by Kaul (2011), namely lack of information, free riding and policy neglect, thereby underpinning targeted conservation and restoration projects designed to maintain or improve the provision of regulating ecosystem services.

Further research could take a series of flood risk scenarios, knowledge about upstream soil and vegetation conditions which impact runoff coefficients, and then model specific actions to restore 
vegetation and soil health on peri-urban slopes to reduce downstream flood risk (Barbedo et al., 2014). For instance, the peri-urban areas with high runoff coefficients close to the eastern and southern neighbourhoods in Mexico City that have reported severe flood events (see Figure 3) could be targeted for interventions, e.g. to restore vegetation and soils. Beyond our four case study areas, understanding the insurance value provided by peri-urban ecosystems could support targeted interventions for the 70 Mexican cities at high risk of flooding that are without flood insurance, see Table 3.

Additionally future research could incorporate information on the existence of hazard insurance and assess the institutional capacity of a region or nation to manage a catastrophic event. In Mexico the government has adopted a number of initiatives to reduce its vulnerability to climate change such as forest resource management, watersheds conservation and coastal management (INECC, 2018). A recent effort to systematise relevant information is the National Atlas of Vulnerability to Climate Change that presents maps that show territorial vulnerability to climate change and guidance on adaptation strategies for municipal governments ${ }^{1}$. To improve policy design and relevance detailed information about the potential to reduce hazards in urban contexts is urgently needed. In the recent 'A Strategic Evaluation of the National Climate Change Policy at the Subnational Level' in a sample of six states and eighteen municipalities there is no evidence of targeted adaptation activities, e.g. reforestation and forest management, to reduce natural hazard vulnerability (INECC, 2018).

Mexico has four hazard insurance schemes however these are not integrated, are underwritten by different departments and do not consider the insurance value of ecosystem services. However, the Cancun insurance-for-nature scheme provides an example of how benefiting areas can contribute

\footnotetext{
${ }^{1}$ Available at: https://atlasvulnerabilidad.inecc.gob.mx/
} 
to ensure on-going storm surge protection. This novel scheme has not yet changed how the National Insurance and Bonding Companies Commission establishes parameters that are considered when estimating the cost of insurance pay-outs for hurricanes and floods (DOF, 2015). For floods, data about precipitation and runoff conditions are considered but there is no explicit information about slope and vegetation when calculating risk. These guidelines could be improved by considering how improved conditions for vegetation and soil in peri-urban areas can reduce runoff coefficients and reduce urban flood risk.

In an international context, the USA's Community Rating System (CRS) combines financial and natural insurance. Brody et al. (2009) in a review of the implementation of the CRS programme during 1999-2005 in Florida, found that local authorities responded to CRS incentives, implementing straightforward activities that generate large premium savings to residents. The authors recommend modifying the CRS reward structure to incentivise the adoption of more costly and complex activities that have the potential to accelerate flood resilience. It does not however take into account the spatial relationships between the areas of demand and supply for flood regulation. Adding this element could provide a potential model not only to connect flood-prone residents and insurers but also flood-prone residents and upstream peri-urban ecosystems. For instance, the scheme could incentivise interventions to reduce runoff.

In operationalising insurance value, local communities that manage areas that provision regulating ecosystem services have an opportunity to benefit. Peri-urban areas and ejidos that have received little policy attention might be the new centres of marketed services (Lamarque et al. 2011). Community management in areas targeted for investment in regulating ecosystem services through restoration and conservation holds promise. At this local level, traditional ecological knowledge has an important impact on social-ecological practices and mechanisms fundamental for biodiversity conservation (Berkes et al., 2000). Policy interventions are more likely to succeed when there is a 
good understanding of stakeholders' perceptions of ecosystem services. Current incentives for local communities to manage land and biodiversity is focussed on the provision of those ecosystem services of importance to them and not necessarily non-marketed services of importance to other communities (Lamarque et al., 2011). For instance, Soto and Alfie (2019) worked with two droughtprone peri-urban communities in Mexico to examine local benefits and incentives for restoring natural capital. New incentives could extend community management activities for the benefit of downstream, nearby or inland urban areas.

Reconciling the spatial and temporal scales required to protect the value of natural insurance provided by ecosystems will in some cases result in a public-private partnership like that for the Mesoamerican coral reef. The role of partnerships and effective governance are highlighted as critical for implementation of policy instruments around ecosystem service provision (IPBES, 2018). In those instances, where poorer populations are exposed to hazards and private partners are unlikely, this research demonstrates that policymakers have incentives to maintain natural ecosystems that increase natural protection in lieu of ever-increasing reconstruction costs. There are other initiatives such as the Zurich Flood Resilience Alliance that works in different counties, including in Mexico, which aims to work through multi-sector partnership to strengthen communities' resilience to floods. ${ }^{2}$ In fact, the sustainability office of the Zurich Insurance Group in Mexico City learnt about this research and plan to extend this conceptual framework and analysis to implement their next reforestation campaign in Mexico City. The link to ecosystems is a way to provide new information to city authorities about flood risk management.

Nevertheless, the certainty and clear lines of responsibility in the event of failure provided by engineered mitigation strategies will likely mean continued preference for such investments over

\footnotetext{
${ }^{2}$ https://www.zurich.com/en/sustainability/flood-resilience
} 
nature-based solutions (Geaves and Penning-Rowsell, 2014; Gasparatos, 2015). Yet, as levels of protection diminish, and for those areas without engineered infrastructure, interest in natural insurance will likely grow. In both cases, the critical role of natural insurance is the buffer it provides against a range of risks and scenarios (Tinch, 2015). Long-term land-use and conservation planning to protect and restore ecosystem services, with fair and negotiated cost sharing (Gómez-Baggethun et al., 2013) will necessitate improvements in decision support systems that integrate the insurance value of ecosystems in hazard management.

In this research, we present general characteristics of 384 cities and their peri-urban areas, but focus only on four out of 71 urban areas classified at high or very high flood risk. This spatial analysis could be extended to other flood prone cities as well as to the 137 cities classified as at high and very high risk of drought. This assumes peri-urban ecosystems provision drought-relevant regulating ecosystem services. Sidibé et al. (2018) find that soil biodiversity through its water storage function acts as natural insurance against drought in rainfed agriculture. This suggests that integrated policy could mainstream targeted protection of the insurance value of biodiversity to reduce multiple risks.

New focus on peri-urban areas could contribute to biodiversity conservation and climate change resilience. Researchers have quantified the benefits peri-urban ecosystem services provide to urban residents under various future scenarios across human health and hazard risk (Harman and Choy, 2011; Barbedo et al., 2014; Su et al., 2014; Calderon and Quiroz, 2017). A more strategic, integrated approach could spatially target conservation and restoration of those aspects of ecosystems that provide insurance value across hazards and develop co-funding with at-risk populations.

\section{Conclusions}


In the paper, we investigate steps to operationalise the insurance value of peri-urban areas. Our spatial analysis provides examples of how to link regulating ecosystem service restoration and conservation to provide solutions to increasing multiple risks under climate change. The conceptual framework developed and applied here provides another step to inform risk management policies, better adaptation strategies and incentivise new hazard insurance schemes.

On a policy level, this requires long-term planning and funding to protect those aspects that provide insurance value and the identification of public-private partnerships including the design of insurance schemes to incentivise risk reduction, damage mitigation and to co-fund ecosystem service restoration following hazard damage. Mexico has developed some institutional capacity for risk management. Nevertheless, most official data is provided at the state level scale and does not adequately cover urban areas. The inclusion of the insurance value into insurance schemes and risk management information tools, with spatial analysis, would strengthen Mexico's capacity to mitigate risks. This research has illustrated the potential to produce a decision-making tool at smaller geographical scales, to suggest new policy interventions and to identify additional research needs, such as runoff scenarios and damage cost estimates for different flood events.

New policy that connects urban communities to their catchments could provide impetus to minimise land-use change in peri-urban areas as a hedge against multiple risks. Urban residents are affected more often and by more severe flood events and thus might be ready to adopt solutions that protect them against these losses. By connecting benefiting to providing areas there is a possibility to develop insurance schemes that pay to reduce risk. Maintaining or enhancing the insurance value currently provided as a public good will involve land management and there is opportunity in Mexico to engage ejido communities to conserve those aspects of their lands that underpin this insurance value. A co-benefit would be that such investment would also enhance in situ resilience critical to these vulnerable communities. Lessons learned in the operationalisation of 
insurance value in policy and insurance practice could be transferred to other vulnerable communities worldwide.

\section{Acknowledgements}

G. Soto was supported by a Researcher Links grant, ID RLTG9-LATAM·358703065, under the Newton Fund Latin America Researcher Links Travel Grants partnership. The grant is funded by the UK Department of Business, Energy and Industrial Strategy (BEIS) and delivered by the British Council. For further information, please visit www.newtonfund.ac.uk. We are very grateful to Professor Kerry Turner for his valuable suggestions on this research. We wish to thank Socorro Flores, researcher at the Laboratory of Socio-territorial Analysis (LAST) for her expert recommendation on specific data sources and data processing. We thank Lessli Ramirez, Jesús Romero and Aidet Peralta, students from the B.A. in Socio-territorial Studies for their assistance with some of the GIS data processing. We also thank two anonymous reviewers for their constructive comments and the Special Issue Editors, Professors Eeva Primmer and Jouni Paavola, for their thorough and helpful advice.

\section{References}

Alfieri, L., Pappenberger, F., \& Wetterhall, F. (2014). The extreme runoff index for flood early warning in Europe. Natural Hazards and Earth System Sciences, 14(6), 1505-1515.

https://doi.org/10.5194/nhess-14-1505-2014

Bagstad, K. J., Johnson, G. W., Voigt, B., \& Villa, F. (2013). Spatial dynamics of ecosystem service flows: A comprehensive approach to quantifying actual services. Ecosystem Services, 4, 117-125. https://doi.org/10.1016/j.ecoser.2012.07.012 
Barbedo, J., Miguez, M., van der Horst, D., \& Marins, M. (2014). Enhancing ecosystem services for flood mitigation: a conservation strategy for peri-urban landscapes? Ecology and Society, 19(2). https://doi.org/10.5751/ES-06482-190254

Baró-Suárez et al. (2011) Costo más probable de daños por inundación en zonas habitacionales de México. Tecnología y Ciencias del Agua. vol. II, núm. 3, p. 201-218.

Baumgärtner, S. (2008). The Insurance Value of biodiversity in the Provision of Ecosystem Services. Natural Resource Modeling, 20(1), 87-127. https://doi.org/10.1111/j.1939-7445.2007.tb00202.x

Baumgärtner, S., \& Strunz, S. (2014). The economic insurance value of ecosystem resilience. Ecological Economics, 101, 21-32. https://doi.org/10.1016/j.ecolecon.2014.02.012

Berkes, F., Colding, J., \& Folke, C. (2000). Rediscovery of Traditional Ecological Knowledge as Adaptive Management. Ecological Applications, 10(5), 1251. https://doi.org/10.2307/2641280

Bray, D. B., Antinori, C., \& Torres-Rojo, J. M. (2006). The Mexican model of community forest management: The role of agrarian policy, forest policy and entrepreneurial organization. Forest Policy and Economics, 8(4), 470-484. https://doi.org/10.1016/j.forpol.2005.08.002

Brody, S. D., Zahran, S., Highfield, W. E., Bernhardt, S. P., \& Vedlitz, A. (2009). Policy Learning for Flood Mitigation: A Longitudinal Assessment of the Community Rating System in Florida. Risk Analysis, 29(6), 912-929. https://doi.org/10.1111/i.1539-6924.2009.01210.x

Calderón-Contreras, R., \& Quiroz-Rosas, L. E. (2017). Analysing scale, quality and diversity of green infrastructure and the provision of Urban Ecosystem Services: A case from Mexico City. Ecosystem Services, 23, 127-137. https://doi.org/10.1016/j.ecoser.2016.12.004

Cartron, J.-L. E., Ceballos, G., \& Felger, R. S. (Eds.). (2005). Biodiversity, ecosystems, and conservation in northern Mexico. Oxford; New York: Oxford University Press. 
CENAPRED. (2012a). Grado de peligro por presencia de ciclones tropicales por municipio. Distrito Federal. Retrieved from http://www.conabio.gob.mx/informacion/metadata/gis/prescictgw.xml?_httpcache=yes\&_xsl=/d b/metadata/xsl/fgdc_html.xsl\&_indent=no

CENAPRED. (2012b). Grado de peligro por sequía por municipio. Retrieved from http://www.conabio.gob.mx/informacion/metadata/gis/pelsequigw.xml?_httpcache=yes\&_xsl=/d b/metadata/xsl/fgdc_html.xsl\&_indent=no

CENAPRED. (2017). Índice de peligro por inundaciones a nivel municipal. Retrieved from http://www.iingen.unam.mx/es$\underline{\mathrm{mx} / \text { BancoDelnformacion/MemoriasdeEventos/Riesgoporlnundaciones/01 Lunes/METODOLOGiA }}$ SPROPUESTASCENAPRED.pdf

CONABIO (2004). Regiones terrestres prioritarias. Catálogo de metadatos geográficos. Comisión Nacional para el Conocimiento y Uso de la Biodiversidad. Retrieved from: http://www.conabio.gob.mx/informacion/gis/ CONABIO (2016). Sitios de atención prioritaria para la conservación de la biodiversidad. Catálogo de metadatos geográficos. Comisión Nacional para el Conocimiento y Uso de la Biodiversidad. Retrieved from: http://www.conabio.gob.mx/informacion/metadata/gis/sap gw.xml? httpcache=yes\& xsl=/db/m etadata/xsl/fgdc html.xsl\& indent=no

CONAPO (2010). Indice de marginación por localidad 2010. Consejo Nacional de Población. 
Cruz-Bello, G. M., \& Sotelo-Ruiz, E. D. (2013). Coupling Spatial Multi-Attribute Analysis and Optimization to Identify Reforestation Priority Areas: A Case Study in Central Mexico. Mountain Research and Development, 33(1), 29-39. https://doi.org/10.1659/MRD-JOURNAL-D-12-00085.1

Czamanski, D. (2008). Urban Sprawl and Ecosystems - Can Nature Survive? International Review of Environmental and Resource Economics, 2(4), 321-366. https://doi.org/10.1561/101.00000019

De Groot, R.S., Blignaut, J., Van der Ploeg, S., Aronson, J., Elmqvist, T., Farley, J. (2013). Benefits of investing in ecosystem restoration. Conservation Biology, 27(6): 1286-1293.

Diaz-Chavez, R. (2006). Measuring sustainability in peri-urban areas: case study of Mexico City. The Peri-Urban Interface. Approaches to Sustainable Natural and Human Resource Use. Earthscan. London, 246-261.

DOF (2015). Anexo 5.1.6-a. Bases técnicas para el cálculo de la prima de riesgo y de la pérdida máxima probable de los seguros de huracán y otros riesgos hidrometeorológicos. Anexos de la circular única de seguros y fianzas. Disposiciones de carácter general derivadas de la ley de instituciones de seguros y de fianzas. Secretaría de Hacienda y Crédito Público, Comisión Nacional de Seguros y Fianzas. Retrived from http://www.dof.gob.mx/nota_detalle.php?codigo=5387210\&fecha=30/03/2015

Elmqvist, T., Folke, C., Nyström, M., Peterson, G., Bengtsson, J., Walker, B., \& Norberg, J. (2003). Response diversity, ecosystem change, and resilience. Frontiers in Ecology and the Environment, 1(9), 488-494. https://doi.org/10.1890/1540-9295(2003)001[0488:RDECAR]2.0.CO;2

European Environment Agency. (2018). The Common International Classification of Ecosystem Services (CICES). Retrieved August 22, 2018, from https://cices.eu/resources/ 
FAO. (2016). Mexico: Country fact sheet on food and agriculture policy trends. Food and Agriculture Policy Decision Analysis team.

FEMA, Federal Insurance and Mitigation Administration. (2018). National Flood Insurance Program: Community Rating System. A local official's guide to saving lives, preventing property damage, and reducing the cost of flood insurance. FEMA B 573/2018.

Figueroa, E., Pasten, R. (2015). The economic value of forests in supply local climate regulation. The Australian Journal of Agricultural and Resource Economics, 59: 446-457.

Fischer, M. (2018). "The IPBES regional assessment on biodiversity and ecosystem services for Europe and Central Asia: Trends, drivers and options for decision-making." ESP Regional Conference, Ecosystem services in a change world: moving from theory to practice. San Sebastian, Spain, 16, October 2018.

Fischer, J., Lindenmayer, D. B., et al. (2006). Biodiversity, ecosystem function, and resilience: ten guiding principles for commodity production landscapes. Frontiers in Ecology and the Environment, 4, 80-86.

Fisher, B., Turner, R. K., Morling, P. (2009). Defining and classifying ecosystem services for decision making. Ecological Economics, 68(3), 643-653. https://doi.org/10.1016/j.ecolecon.2008.09.014

Fisher, J. A., Patenaude, G., Giri, K., Lewis, K., Meir, P., Pinho, P. Rounsevell, M. D. A., Williams, M. (2014) Understanding the relationships between ecosystem services and poverty alleviation: A conceptual framework. Ecosystem Services, 7: 34-45.

García, E. (1998). Climas (clasificación de Koppen, modificado por García). Escala 1:1000000. México. Comisión Nacional para el Conocimiento y Uso de la Biodiversidad (CONABIO). 
Gasparatos, A. (2015). What is the insurance value of urban ecosystems and their services? The nature of cities. https://www.thenatureofcities.com/2015/09/29/what-is-the-insurance-value-ofurban-ecosystems-and-their-services/

Geaves, L.H., Penning-Rowsell, E.C. (2016) Flood Risk Management as a public or a private good, and the implications for stakeholder engagement, Environmental Science \& Policy, 55: 281-291.

Geaves, L.H., Penning-Rowsell, E.C. (2014). 'Contractual' and 'cooperative' civic engagement: the emergence and roles of 'flood action groups' in England and Wales, Ambio 1-12.

Gómez-Baggethun, E., de Groot, R., Lomas, P. L., \& Montes, C. (2010). The history of ecosystem services in economic theory and practice: From early notions to markets and payment schemes. Ecological Economics, 69(6), 1209-1218. https://doi.org/10.1016/j.ecolecon.2009.11.007

Gordon, P., Little, R. (2009). Rethinking flood protection: Options and opportunities for New Orleans. Public Works Management \& Policy, 14(1), 37-54.

Harman, B., Choy, D. L. (2011). Perspectives on tradable development rights for ecosystem service protection: lessons from an Australian peri-urban region. Journal of Environmental Planning and Management, 54(5), 617-635. https://doi.org/10.1080/09640568.2010.526405

Harvey, F. (2017). Mexico launches pioneering scheme to insure its coral reef. The Guardian. Retrieved from https://www.theguardian.com/environment/2017/jul/20/mexico-launchespioneering-scheme-to-insure-its-coral-reef

Heal, G. M. (2000). Nature and the marketplace: capturing the value of ecosystem services. Washington, D.C: Island Press. 
Instituto Nacional de Ecología y Cambio Climático (INECC). (2018). Evaluación Estratégica del avance subnacional de la Política Nacional de Cambio Climático. Mexico. Retrieved from http://cambioclimatico.gob.mx:8080/xmlui/handle/publicaciones/227

Instituto Nacional de Estadística y Geografía (INEGI). (2010). Censo de Población y Vivienda 2010. Principales resultados por localidad (ITER). México, D.F. Retrieved from http://www3.inegi.org.mx/sistemas/tabuladosbasicos/tabentidad.aspx?c=33713\&s=est

Instituto Nacional de Estadística y Geografía (INEGI). (2014). Marco geoestadístico 2014 versión 6.2 (DENUE). Mexico. Retrieved from http://www.beta.inegi.org.mx/app/biblioteca/ficha.html?upc=702825004386 Instituto Nacional de Estadística y Geografía (INEGI). (2015). Directorio Estadístico Nacional de Unidades Económicas. México, D.F.

Instituto Nacional de Estadística y Geografía (INEGI). (2016a). Conociendo México (Sexta edición). México, D.F.

Instituto Nacional de Estadística y Geografía (INEGI). (2016b). Marco Censal Agropecuario 2016. Mexico: INEGI. Retrieved from http://www.inegi.org.mx/est/contenidos/proyectos/accesomicrodatos/amca/default.aspx IPBES (2018): Summary for policymakers of the regional assessment report on biodiversity and ecosystem services for the Americas of the Intergovernmental Science-Policy Platform on Biodiversity and Ecosystem Services. J. Rice, C.S. Seixas, M.E. Zaccagnini, M. BedoyaGaitán, N. Valderrama, C.B. Anderson, M.T.K. Arroyo, M. Bustamante, J. Cavender-Bares, A. Diaz-de-Leon, S. Fennessy, J. R. García Márquez, K. Garcia, E.H. Helmer, B. Herrera, B. Klatt, J.P. Ometo, V. 
Rodríguez Osuna, F.R. Scarano, S. Schill and J. S. Farinaci (eds.). IPBES secretariat, Bonn, Germany. 41 pages.

Johnson G, Bagstad K, Snapp R, Villa F. 2010. Service path attribution networks (SPANs): Spatially quantifying the flow of ecosystem services from landscapes to people. In: Taniar D, Gervasi O, Murgante B, Pardede E, Apduhan B, editors. Computational science and its applications - ICCSA 2010, vol 6016. Lecture notes in computer science. Berlin / Heidelberg: Springer, pp 238-253. DOI: 10.1007/978-3-642-12156-2_18

Kaul, I. (2012). Global public goods: Explaining their underprovision. Journal of International Economic Law, 15(3): 729-750.

Kellet, J., Way, M. (2018). Reefs for resilience: Insuring our shared natural capital. United Nations Development Programme Blog posted on June 6, 2018.

http://www.undp.org/content/undp/en/home/blog/2018/Reefs-for-resilience-Insuring-ourshared-natural-capital.html

Kremer, P., Andersson, E., McPhearson, T., \& Elmqvist, T. (2015). Advancing the frontier of urban ecosystem services research. Ecosystem Services, 12, 149-151.

https://doi.org/10.1016/j.ecoser.2015.01.008

Lamarque, P., Tappeiner, U., Turner, C., Steinbacher, M., Bardgett, R. D., Szukics, U., ... Lavorel, S. (2011). Stakeholder perceptions of grassland ecosystem services in relation to knowledge on soil fertility and biodiversity. Regional Environmental Change, 11(4), 791-804.

https://doi.org/10.1007/s10113-011-0214-0 
Martin-Ortega, J., Ojea, E., \& Roux, C. (2013). Payments for Water Ecosystem Services in Latin America: A literature review and conceptual model. Ecosystem Services, 6, 122-132.

https://doi.org/10.1016/j.ecoser.2013.09.008

McGregor, D. F. M., Simon, D., \& Thompson, D. A. (Eds.). (2006). The peri-urban interface:

approaches to sustainable natural and human resource use. London ; Sterling, VA: Earthscan.

McPhearson, T., Andersson, E., Elqvist, T., Frntzeskaki, N. (2015). Resilience of and through urban ecosystem services. Ecosystem Services, 12: 152-156.

Mendoza, M., Bocco, G., López G. E., Bravo, M. (2002). Implicaciones hidrológicas del cambio de la cobertura vegetal y uso del suelo: una propuesta de análisis espacial a nivel regional en la cuenca cerrada del lago de Cuitzeo, Michoacán. Investigaciones Geográficas, (49), 92-117.

Mueller, J. M., W. Swaffar, E. A. Nielsen, A. E. Springer, and S. M. Lopez (2013), Estimating the value of watershed services following forest restoration, Water Resour. Res., 49, 1773-1781, doi:10.1002/wrcr.20163.

Muñoz-Piña, C., Guevara, A., Torres, J. M., \& Braña, J. (2008). Paying for the hydrological services of Mexico's forests: Analysis, negotiations and results. Ecological Economics, 65(4), 725-736. https://doi.org/10.1016/j.ecolecon.2007.07.031

Nature Conservancy. (2018, March 9). The Nature Conservancy and the Government of Quintana Roo announce innovative financial mechanism for insuring and conserving coral reefs. Retrieved from https://www.preventionweb.net/go/57410

OECD. (2013). OECD Environmental Performance Reviews: Mexico 2013. OECD Publishing. https://doi.org/10.1787/9789264180109-en 
Protección Civil (2018). Recursos Autorizados por declaratoria de Desastre.

http://www.proteccioncivil.gob.mx/es/ProteccionCivil/Recursos_Autorizados_por_Declaratoria_d e_Desastre

Quaas, M. F., Baumgärtner, S. (2008). Natural vs. financial insurance in the management of publicgood ecosystems. Ecological Economics, 65(2), 397-406.

https://doi.org/10.1016/j.ecolecon.2007.07.004

Quaas, M. F., Baumgärtner, S. (2008). Natural vs. financial insurance in the management of publicgood ecosystems. Ecological Economics, 65(2), 397-406.

https://doi.org/10.1016/j.ecolecon.2007.07.004

Romero Sánchez, G. (2017, June 2). Asegurado, el pago de daños por inundaciones, afirma Mancera. La Jornada, p. 30.

Sarukhán, J., et al. 2009. Capital natural de México. Síntesis: conocimiento actual, evaluación y perspectivas de sustentabilidad. Comisión Nacional para el Conocimiento y Uso de la Biodiversidad, México Sarukhán, J., Urquiza-Haas, T., Koleff, P., Carabias, J., Dirzo, R., Ezcurra, E., ...

Sarukhán, J., Urquiza-Haas, T., Koleff, P., Carabias, J., Dirzo, R., Ezcurra, E., Cerdeira-Estrada, S., Soberón, J. (2015) Strategic Actions to Value, Conserve, and Restore the Natural Capital of Megadiversity Countries: The Case of Mexico. Bioscience, 65(2): 164-173.

Serna-Chavez, H. M., Schulp, C. J. E., van Bodegom, P. M., Bouten, W., Verburg, P. H., \& Davidson, M. D. (2014). A quantitative framework for assessing spatial flows of ecosystem services. Ecological Indicators, 39, 24-33. https://doi.org/10.1016/j.ecolind.2013.11.024 
Sidibé, Y., Foudi, S., Pascual, U, Termansen, M. (2018). Adaptation to climate change in rainfed agricultura in the Global South: Soil biodiversity as natural insurance. Ecological Economics, 146 (2018): 588-596.

Soto-Montes-de-Oca, G., Alfie-Cohen, M. (2019). Impact of climate change in Mexican peri-urban areas with risk of drought. Journal of Arid Environments, 162, 74-88.

https://doi.org/10.1016/j.jaridenv.2018.10.006

Styles, D., Borjesson, P., et al. 2016. Climate regulation, energy provisioning and water purification: Quantifying ecosystem service delivery of bioenergy willow grown on riparian buffer zones using life cycle assessment. Ambio, 45, 872-884.

Su, S., Wang, Y., Luo, F., Mai, G., \& Pu, J. (2014). Peri-urban vegetated landscape pattern changes in relation to socioeconomic development. Ecological Indicators, 46, 477-486.

https://doi.org/10.1016/j.ecolind.2014.06.044

Tinch, R. (2015). What is the insurance value of urban ecosystems and their services? The nature of cities. https://www.thenatureofcities.com/2015/09/29/what-is-the-insurance-value-of-urbanecosystems-and-their-services/

Valdez, R., GuzmáN-Aranda, J. C., Abarca, F. J., Tarango-AráMbula, L. A., \& SáNchez, F. C. (2006). Wildlife Conservation and Management in Mexico. Wildlife Society Bulletin, 34(2), 270-282. https://doi.org/10.2193/0091-7648(2006)34[270:WCAMIM]2.0.CO;2

World Bank. (2011). Insuring Against Natural Disaster Risk in Mexico. The Treasury. June 20, 2011.

World Bank. (2017). Disaster risk as a tool for development. A Summary of Findings from the Disaster Risk Finance Impact Analytics Project. 
